University of Nebraska - Lincoln

DigitalCommons@University of Nebraska - Lincoln

Spring 2004

\title{
The Process of Recommending Homework in Psychotherapy: A Review of Therapist Delivery Methods, Client Acceptability, and Factors That Affect Compliance
}

\author{
Michael J. Scheel \\ University of Nebraska-Lincoln, mscheel2@unl.edu \\ William E. Hanson \\ University of Nebraska-Lincoln \\ Tanya I. Razzhavaikina \\ University of Nebraska-Lincoln
}

Follow this and additional works at: https://digitalcommons.unl.edu/psychfacpub

Part of the Psychiatry and Psychology Commons

Scheel, Michael J.; Hanson, William E.; and Razzhavaikina, Tanya I., "The Process of Recommending Homework in Psychotherapy: A Review of Therapist Delivery Methods, Client Acceptability, and Factors That Affect Compliance" (2004). Faculty Publications, Department of Psychology. 372.

https://digitalcommons.unl.edu/psychfacpub/372

This Article is brought to you for free and open access by the Psychology, Department of at DigitalCommons@University of Nebraska - Lincoln. It has been accepted for inclusion in Faculty Publications, Department of Psychology by an authorized administrator of DigitalCommons@University of Nebraska - Lincoln. 
Published in Psychotherapy: Theory, Research, Practice, Training 41:1 (Spring 2004), pp. 38-55; doi 10.1037/0033-

3204.41.1.38 Copyright ( 2004 Educational Publishing Foundation; published by the American Psychological

Association. Used by permission. "This article may not exactly replicate the final version published in the

APA journal. It is not the copy of record."

\title{
The Process of Recommending Homework in Psychotherapy: A Review of Therapist Delivery Methods, Client Acceptability, and Factors That Affect Compliance
}

\author{
Michael J. Scheel, William E. Hanson, and Tanya I. Razzhavaikina \\ Department of Educational Psychology, University of Nebraska-Lincoln \\ Corresponding author - Michael J. Scheel, Department of Educational Psychology, 38 Teachers College Hall, \\ University of Nebraska, Lincoln, NE 68588-0345; email mscheel2@unl.edu
}

\begin{abstract}
Although the link between homework use and positive psychotherapy outcomes has been established, relatively little is known about the therapeutic processes, or factors, that promote homework compliance. Homework compliance may be viewed as an indicator of client commitment and involvement in psychotherapy. This article presents the results of a systematic review of research, including 16 empirical studies, related to the homework recommendation process. Findings relate to the frequency and type of homework that therapists deliver, factors that promote client acceptability of homework recommendations, and factors that affect compliance. On the basis of these findings, the authors propose a theoretically and empirically based, 6-phase conceptual model of the homework recommendation process. They also propose specific strategies for recommending homework to clients and directions for future research.
\end{abstract}

Therapist recommendations to clients to perform out-of-session actions, commonly called homework, are related to positive psychotherapy outcomes. Results of a recent meta-analysis of 27 studies of cognitive and behavioral therapies, representing 375 clients, indicate that this relationship is strong $(r=$ .36 ; $95 \%$ confidence interval $[\mathrm{CI}]=0.23-0.48$; Ka- zantzis, Deane, \& Ronan, 2000). In this study, homework compliance was also significantly correlated with positive outcomes $(r=.22 ; 95 \% \mathrm{CI}=0.22-0.22$; $N=1,327)$. Furthermore, studies indicate that the homework-outcome relationship is linear, with clients who do the most homework improving more than clients who do little or no homework (Burns \& Auerbach, 1992; Burns \& Spangler, 2000; Neimeyer \& Feixas, 1990; Persons, Burns, \& Perloff, 1988; Zettle \& Hayes, 1987). Studies also indicate that cognitive-behavioral therapy (CBT) with homework, compared with CBT without homework, is more effective (Bryant, Simons, \& Thase, 1999; Neimeyer \& Feixas, 1990). Finally, clients who comply with homework recommendations in cognitive therapy have been shown to benefit more than clients who do not (Bryant et al., 1999).

Despite the strong, positive relationship between homework and psychotherapy outcomes, little empirically driven attention has been directed toward studying strategies to use in recommending homework and in gaining compliance from clients to complete homework. Although several reviews related to homework and psychotherapy outcomes have been published (Detweiler \& Whisman, 1999; Glaser, Kazantzis, Deane, \& Oades, 2000; Kazantzis, 2000; Ka- 
zantzis \& Lampropoulos, 2002a, 2002b; Kazantzis et al., 2000), no attempt has been made to review and synthesize research about homework recommendations at the process level. Thus, little is known about how process variables affect, for example, homework compliance. Homework compliance seems especially important because it indicates commitment and involvement on the part of clients, two essential common factors of therapy (Hubble, Duncan, \& Miller, 1999).

The lack of emphasis on a systematic, empirically based homework recommendation process that may be applied across a variety of treatments and theoretical models is curious, especially considering the field's current emphasis on empirically supported treatments. Homework is embedded in manualized treatment approaches for CBT (e.g., A. T. Beck, Rush, Shaw, \& Emery, 1979), systemic forms of therapy (e.g., Boscolo, Cecchin, Hoffman, \& Penn, 1987), and solution focused therapy (e.g., DeJong \& Berg, 2002). Furthermore, a survey by Kazantzis and Deane (1999) of psychotherapy practitioners indicated that homework practices are routine strategies in most therapists' work, independent of theoretical orientation. The importance of common factors in psychotherapy and the contributions that they make to therapy outcome has been clearly demonstrated (Hubble et al., 1999; Wampold, 2001). Homework recommendation, as a discrete clinical activity, provides an excellent opportunity to study and promote common factors that are so important to the psychotherapy change process. If, for example, therapists gain compliance for homework tasks, they may also gain degrees of motivation, commitment, and involvement from clients; overcome client resistance to psychotherapy; and ultimately introduce into a client's existing coping style the possibility of a tangible and understandable change process.

An important development contributing to the "legitimization" of homework in psychotherapy, defined here as (a) the act by the therapist of recommending either implicitly or explicitly to the client the performance of specific, between-session actions; (b) the client's attitudinal response to the recommended action; and (c) the out-of-session actions of the client consistent with the recommended homework task, is its inclusion in the Hill and $\mathrm{O}^{\prime}$ Brien (1999) helping-skills model of psychotherapy. Before this, homework was associated in theoretical writ- ings primarily as an exclusive component of brief psychotherapy, cognitive-behavioral approaches, and strategic, structural, and systemic forms of family therapy. It seems now, however, that homework is generally accepted as an essential tool of the psychotherapy change process. If this assertion is true, then it is important that we assess what we know and what we need to explore further about the homework recommendation process in psychotherapy. To this end, we conducted a review of research that focuses on this issue.

The purpose of this review is to highlight what is known currently about homework processes in psychotherapy and to propose a theoretically and empirically based conceptual model of the homework recommendation process. The review does not address questions related to the link between homework and outcome. Instead, we attempt to address the following important questions about homework: (a) What purpose does it serve in psychotherapy? (b) How frequently is it recommended? (c) What types of homework recommendations do therapists deliver? (d) How do clients interpret, or make sense of, these recommendations? (e) What factors promote client acceptability of homework recommendations? and (f) What factors have been shown to affect compliance?

\section{Method}

Sixteen empirical studies were included in this review. The studies, published between 1986 and 2003, were located in eight different refereed journals. For a study to be included, it had to focus on some aspect of the homework recommendation process and be published in English. Fourteen conceptual articles and seven textbooks are also included. These articles and texts were included because for two of the research questions (a and c), no empirical studies were available.

To identify relevant studies and articles, we searched the PsycINFO and ERIC databases using the following terms: compliance with homework, homework implementation, homework completion, acceptability of homework, client commitment to homework, assignment of homework, therapist directives, therapist suggestions, therapist recommendations, therapist prescriptions, out-of-session tasks/actions, and between-session tasks/actions. This search procedure re- 
sulted in 270 matches. Of these matches, 31 (11\%) focused on some aspect of the homework recommendation process and were published in English. As an added step, the references of these 31 matches were back-checked. This ancestry search procedure resulted in the identification of 6 more studies/articles, increasing the overall total to 37 . Of the 37,16 were empirical articles, 14 were conceptual articles, and 7 were textbooks. Table 1 summarizes each of the 16 empirical studies in terms of client populations and characteristics, treatment approaches and durations, key variables, and major findings. Below, we discuss the results, organizing them by the six research questions raised previously.

\section{Results and Discussion}

What Purpose Does Homework Serve in Psychotherapy?

This question may be answered empirically by surveying therapists to obtain their viewpoints. Unfortunately, no such studies were found. Without the existence of empirical evidence, we turned to conceptual articles and theoretical writings. Multiple answers were found, many tied to a specific theoretical orientation. In CBT, for example, homework provides opportunities to practice skills and apply cognitive principles (e.g., exploring assumptions, noticing automatic thoughts) between sessions (A. T. Beck \& Weishaar, 1995). In more collaborative forms of cognitive therapy, homework is a way to test beliefs in daily life and acts as a continuance of themes identified during therapy sessions (A. T. Beck \& Haaga, 1992; J. S. Beck, 1995). In solution focused therapy, observation or behavior tasks are assigned to build solutions (DeJong \& Berg, 2002). Differences from existing interactional patterns are suggested through the assignment of homework, creating opportunities for new experiences and new realities (De Shazer, 1988). In Adlerian marriage counseling, couples do homework to enhance communication and cooperation (Hawes, 1993). In behavior therapy, homework is used to transfer learning to the client's everyday life (Spiegler \& Guevremont, 1998). Corey (2001) offered the view that homework helps clients to assume responsible, active roles in the change process. He describes clients as becoming change agents in their therapy through the use of homework. In strategic therapy, the main goal of homework directives is to encourage clients to behave differently and to modify subjective experiences. Additionally, directives intensify the relationship with the therapist and are used to gather information (Haley, 1991). In an integrative model of object relations, attachment, and cognitive-behavioral theories, Morgan and MacMillan (1999) suggested that homework allows clients to attempt new behaviors that arise from insight, understanding, and cognitive restructuring gained during therapy. They suggest that client actions in between sessions lead to empowerment.

In addition to the above, we offer the following perspectives concerning the purposes of homework. Homework allows for the assessment of progress in psychotherapy through monitoring the success of clients in the performance of tasks. Assessing client cooperation, motivation, or resistance is also possible from homework actions. Results from homework activities may be thought of as small outcomes that may contribute to larger outcomes. Recommending homework also extends therapeutic opportunities by suggesting interventions beyond the 50 -min therapy hour.

\section{How Frequently Is Homework Recommended?}

Homework appears to be recommended often in psychotherapy. Scheel, Seaman, Roach, Mullin, and Blackwell-Mahoney (1999) discovered a homework recommendation in 9 out of 10 sessions in a sample of 109 therapy sessions involving 27 therapists who represented a variety of theoretical orientations. Multiple homework recommendations were provided in more than half of those sessions. Kazantzis and Deane (1999) also offer evidence that homework is a common occurrence. In their survey of 221 therapists, $98 \%$ of respondents reported assigning homework in an average of $57 \%$ of their sessions.

\section{What Types of Homework Recommendations Do Thera- pists Deliver?}

Three different theoretical frameworks and two empirically derived conceptualizations are presented about the types of homework tasks that are assigned in therapy. Hay and Kinnier (1998) offer a framework of homework assignments from their review of the homework literature. Broadly, they classify homework activities of clients as active (e.g., initiating a social interaction), passive (e.g., listening 
to an audiotape), or both (Wells, 1994). According to Hay and Kinnier, types of homework that have appeared in books and articles about various psychotherapy approaches and techniques fall into the following, more specific categories: paradoxical, experiential-behavioral, risk taking and shame attacking, interpersonal, thinking, writing, reading, listening, watching videotape, solution focused, and "don't do anything" assignments.

Brown-Standridge (1989) provided a $2 \times 2 \times 2$ matrix to illustrate the dimensions of a homework task that are applied when considering the appropriateness of the task for a client presentation. The task may be direct (i.e., a behavioral or cognitive task) or indirect (i.e., a metaphorical task, therapeutic suggestion, or message anecdote). The task may also be behavioral or nonbehavioral. Last, it may be paradoxical or nonparadoxical in orientation. Brown-Standridge offers the example of a woman who eats compulsively and whose family insists she lose weight. In anticipation of her resistance, the therapist gives the client a direct, nonbehavioral, paradoxical task, phrased as "Whatever you do this week, don't focus on losing weight."

De Shazer (1988) provides a framework for the assignment of tasks on the basis of the client's motivation with the goal of gaining the client's cooperation. Clients are classified as visitors, customers, or complainants. Visitors take on little or no responsibility for the problem and, therefore, are assigned tasks to think only about what could be solved or changed. Customers have a high level of motivation to solve the problem within counseling and are asked to choose when they would like to perform a task that will act as a solution for the presenting problem. Complainants blame others for the problem and, consequently, are asked to notice only differences when these occur.

Scheel, Seaman, Roach, et al. (1999) formulated the only empirically derived typology of homework types through a content analysis of homework recommendations that occurred during therapy sessions. The categories were (a) social interactions (e.g., practicing assertiveness), (b) stress management (e.g., relaxation exercises), (c) promotion of self-esteem (e.g., positive self-talk, self-nurturance), (d) validation of internal experience (e.g., thought logs), (e) reframing and reconstruction of meaning (e.g., applying metaphors, outside readings), (f) referral (e.g., medical evaluation, group therapy), (g) decision making (e.g., collecting data, considering alternatives), and (h) requests for action (i.e., acting on decisions).

Finally, in an empirical investigation by Mahrer, Nordin, and Miller (1995), the type of homework prescribed was highly related to the type of client presenting problem. For instance, when presenting problems were physical complaints such as headaches, the most frequent assignment was to block the occurrence of the problematic behavior through activities, such as doing relaxation exercises before a headache starts. In another problem category, selfdirected physical bodily acts (e.g., binge eating), the homework that predominated was to carry out problem-reduced behavior, like exposing oneself to binge food and not eating it.

\section{How Do Clients Interpret, or Make Sense of, Homework Recommendations?}

Accurate understanding by the client of what homework the therapist recommends is fundamental and critical to compliance. If the client misunderstands the homework request, the client cannot comply. Homework requests may be implicit or explicit. The therapist may not be aware of suggesting an outof-session action to a client, yet the client may come away from the session with a clear understanding of what the therapist has recommended. The individual realities of therapist and client about homework recommendations may differ. Only a $41 \%$ level of agreement was found in an investigation of therapist and client recall of homework recommendations when each was asked individually and immediately after a counseling session what recommendations had occurred during the session (Scheel, Hoggan, Willie, McDonald, \& Tonin, 1998). Fostering a matched understanding between therapist and client of the homework recommendation that is to be implemented may facilitate accurate adherence to the therapist's treatment plan. Writing out homework recommendations in session, as a physician uses a prescription pad to write out a treatment for a patient, is probably the most explicit method, leaving the least possibility for distortion.

Client deference in the homework recommendation process may also be a significant deterrent to accurate understanding. Client deference may be

(Text continues on page 46.) 


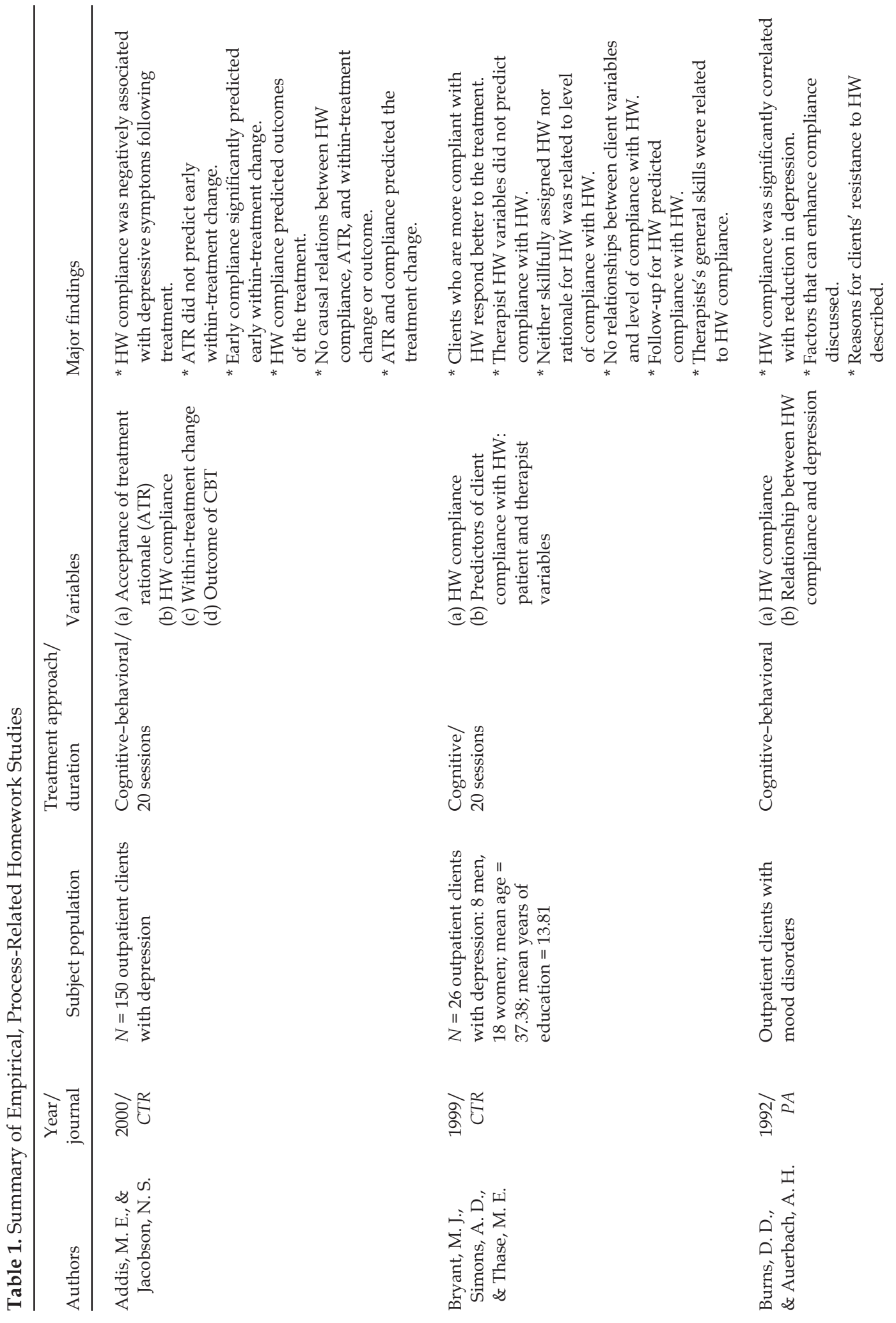




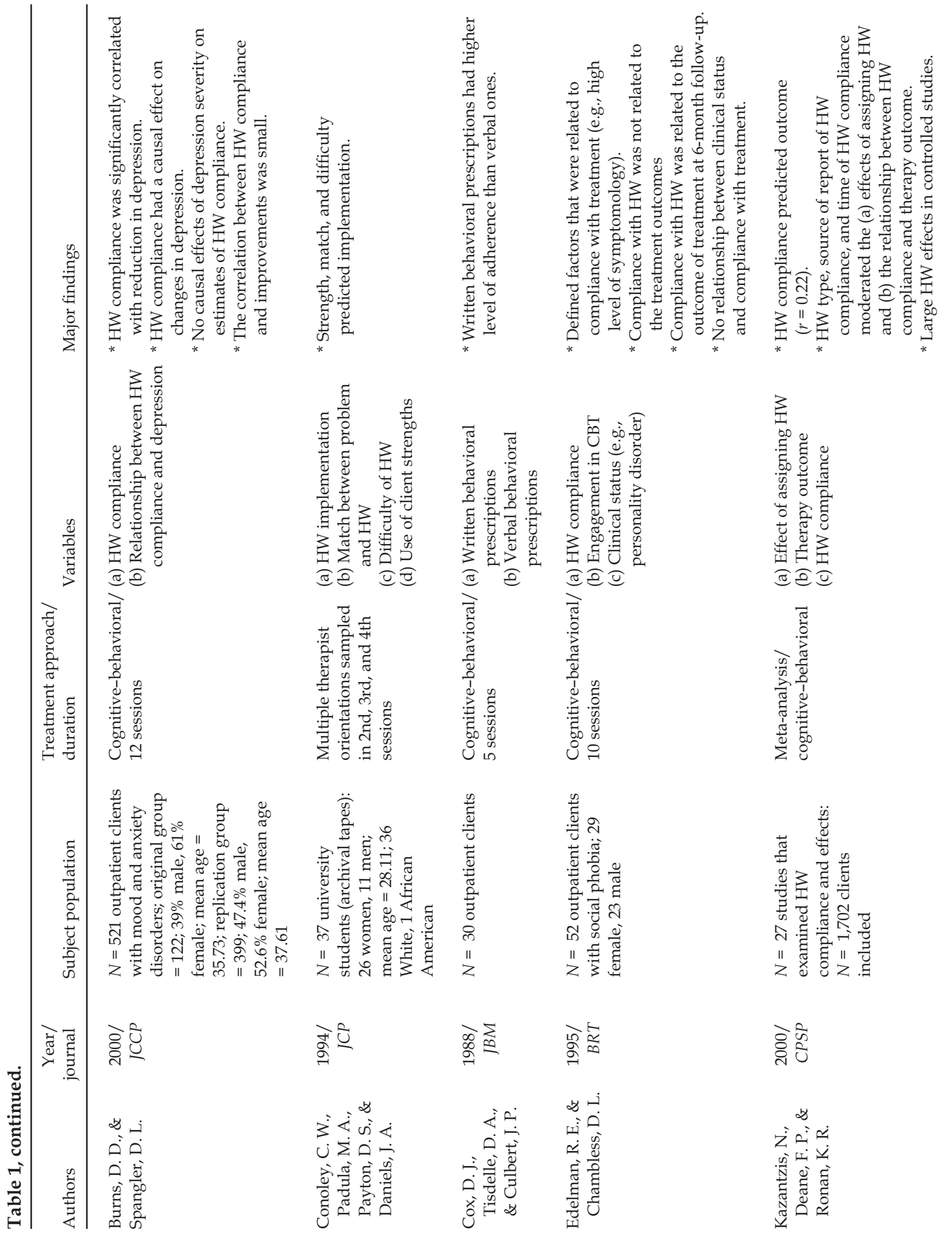




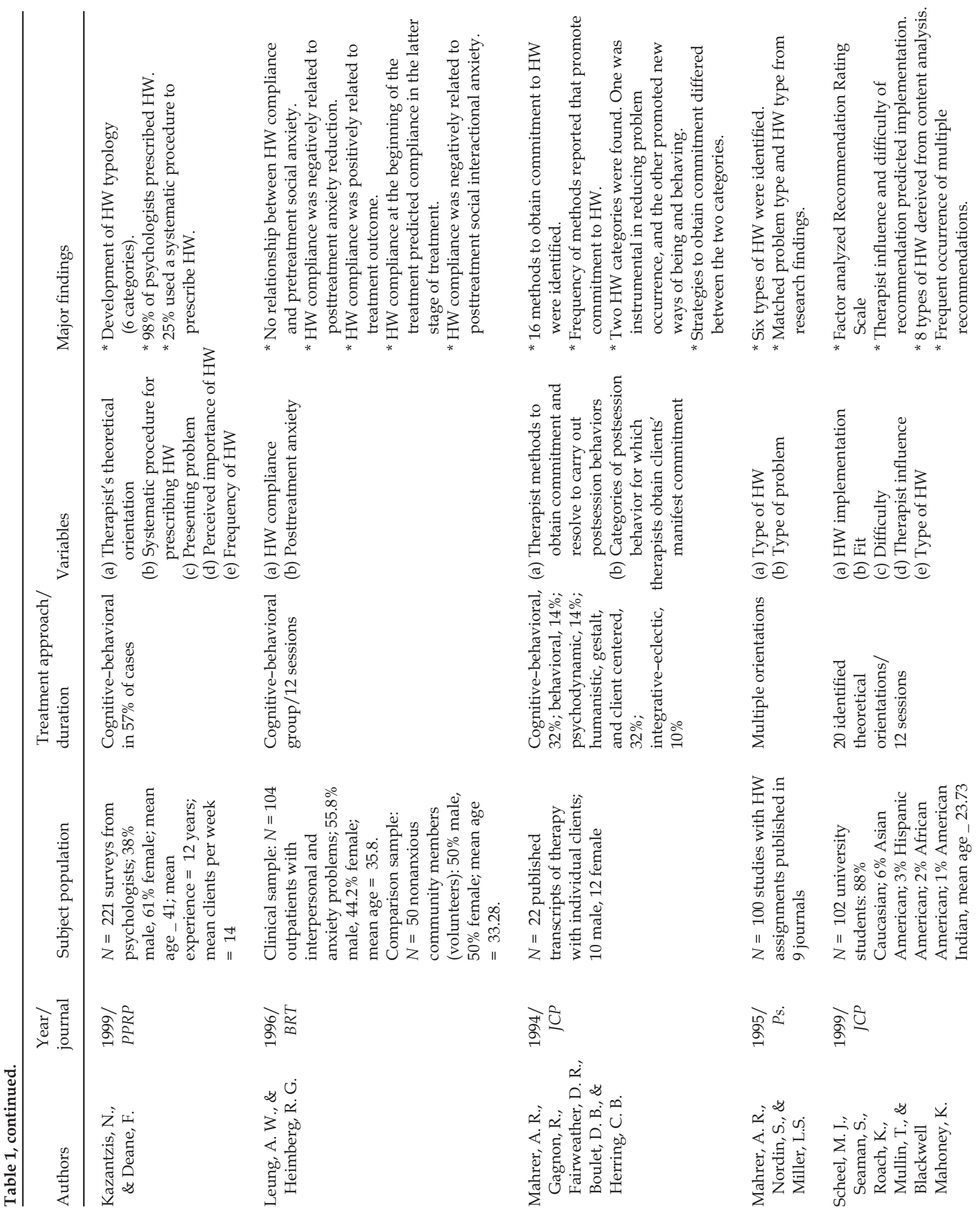




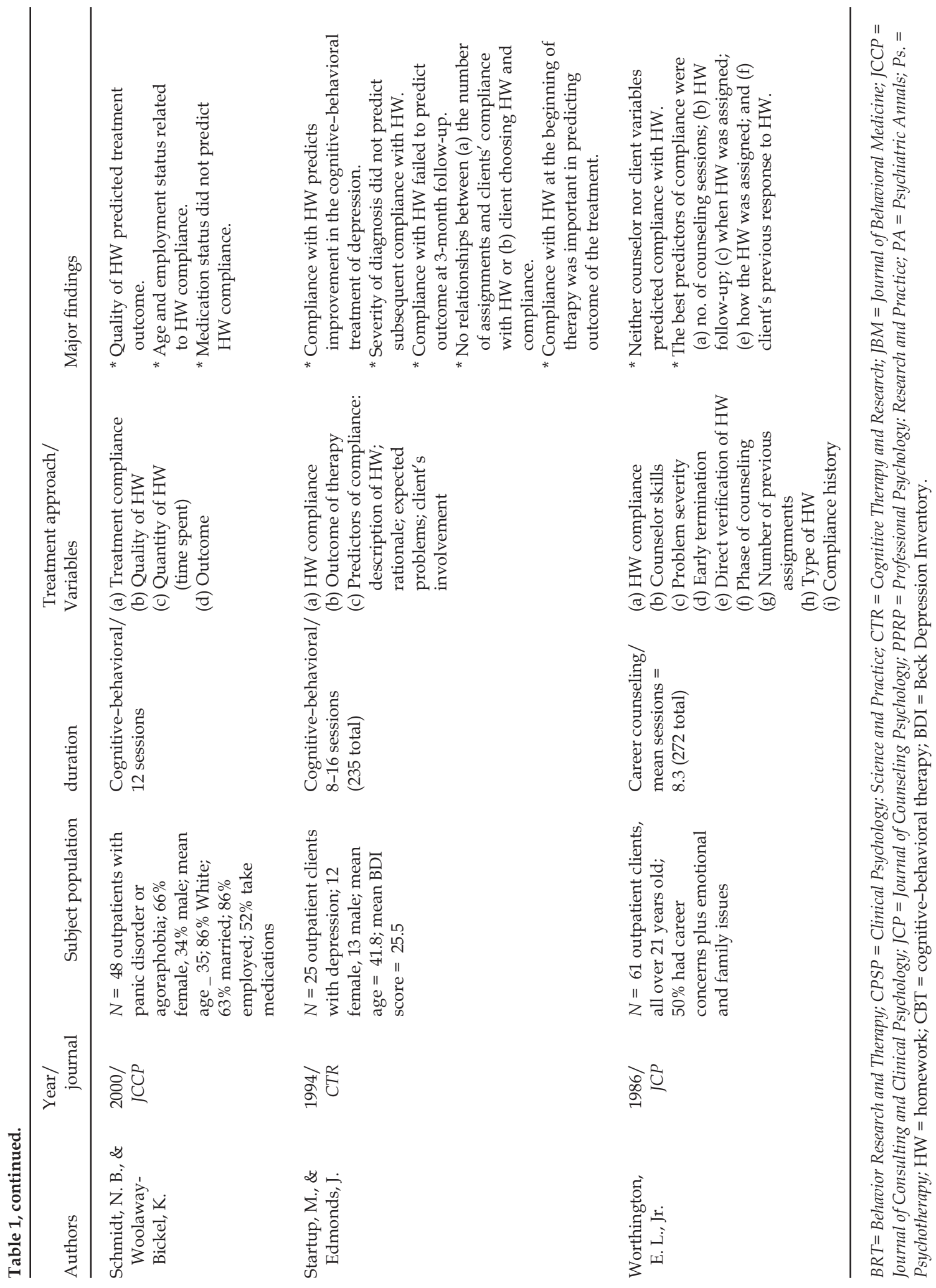


defined as client hesitancy to report openly and honestly negative judgments about the therapist or, in this context, homework recommended by the therapist (Hill, Thompson, Cogar, \& Denman, 1993; Rennie, 1992). A client may want to represent her- or himself in a positive light to the therapist and consequently may not reveal such feelings as dissatisfaction, lack of commitment, confusion, helplessness, or being overwhelmed with the task. Without an open discussion of the task to be completed, differences in understanding between therapist and client cannot be explored. This may be a result of the client's hesitancy to ask for clarification or the therapist's inability to articulate clearly what the task is. An example follows of a mismatch in understanding between client and therapist, taken from the Scheel, Seaman, Roach, et al. (1999) study. Therapist and client were both asked immediately after a counseling session to write down any recommendations for action that were given during the session:

Client's recall: 1) Set aside time for the thoughts that constantly occupy my time and take that time to think about them so that I might have a clearer head throughout the day. 2) Try not to solve everything today. Realize that there is time to work on things.

3) Write thoughts down and be able to look at them, maybe for clarity.

Therapist's recall: 1) Schedule a time each day to vent/express/obsess about the relationship with your ex-boyfriend. Schedule a half hour or hour and confine obsessive thoughts to this allotted time.

Both specifics (amount of time on obsessive thoughts) and purpose (clarity vs. relief from obsessions) differed in this example between therapist and client. Checking the understanding of what is to be done before leaving the session may facilitate the matching of expectations as well as provide a means of accurately assessing whether the recommendation was carried out as intended.

\section{What Factors Promote Client Acceptability of Homework Recommendations?}

We define homework acceptability as the attitudinal component of the client's homework experience. Judgments about acceptability occur when clients evaluate the worth of homework recommendations made by their therapists. The origin of the psychological construct acceptability lies in the behavioral consultation literature with classroom interventions for children's behavioral problems. Kazdin
(1980) originally defined acceptability as "judgments [of acceptability are] likely to embrace evaluation of whether treatment is appropriate for the problem, whether treatment is fair, reasonable, and [nonintrusive], and whether treatment meets with conventional notions about what the treatment should be" (p. 259). Reimers, Wacker, and Koeppl (1987) argued that in order for implementation to occur, acceptability must be gained and the consultee must view the treatment as understandable, effective, and not disruptive. Conoley, Conoley, Ivey, and Scheel (1991) used Reimers et al.'s conceptualization and proposed a three-component model of acceptability in which (a) the consultee perceives a fit between the problem and the treatment; (b) the treatment is viewed as moderately difficult, effective, and humane; and (c) there is a strong consultant-consultee relationship.

Acceptability is a relevant and valid construct for psychotherapy because actions are dependent on the administration of treatment. In consultation, the consultee administers the treatment. In psychotherapy, when out-of-session tasks are suggested, the client may be thought of as administering the treatment. If the client does not find the recommended homework action acceptable, it is unlikely that implementation will occur. It should also be noted that acceptability does not guarantee that the client will actually comply with the proposed homework recommendation. Noncompliance may be due to external influences that act on the client's ability to implement what is recommended. The Conoley et al. (1991) line of acceptability research was applied to the therapist-client relationship and to homework recommendations when, in 1994, Conoley, Padula, Payton, and Daniels (1994) successfully used the concept of acceptability of homework recommendations within a therapistclient context through an analysis of archival videotapes of therapy sessions when a homework recommendation occurred. Their research supported a three-factor predictive model of acceptability, comprising (a) the match between the problem and the recommendation, (b) the difficulty level of the recommendation, and (c) the degree to which the recommendation was built on client strengths.

Scheel, Hoggan, et al. (1998) conducted a follow-up investigation that supported the above three factors and also provided emphasis for client perceptions of the therapist's social influence (expertness, interpersonal attractiveness, and trustworthiness). Evidence from this study supported a predictive model for client implementation of homework recommendations. 
The three factors composing the predictive model were fit of the recommendation, difficulty of the recommendation, and therapist influence. Each factor was significantly correlated with client implementation of the homework recommendation (fit $=.30, p<$ .01 ; difficulty $=.34, p<.01$; influence $=.41, p<.01$ ). This investigation included the construction and validation of the Recommendation Rating Scale (RRS), allowing clients to self-report their acceptability of a proposed homework recommendation.

Results from these studies suggest that four conceptually and empirically overlapping predictive factors are important to client acceptability. These are (a) the fit of the recommendation and accompanying rationale with the client's problem formulation and theory of change, (b) the perceived difficulty (i.e., time, effort, complexity) in executing the recommended action, (c) the utilization of client strengths through the recommendation (e.g., proposing an action that requires verbal skill for a verbal client), and (d) the level of social influence the therapist possesses with the client. Thus, to gain acceptability and to maximize the likelihood of client implementation, the therapist must be perceived by the client as socially influential and must present the recommended homework in a strategic manner intended to match the client's view about her- or himself, the problem, and her or his strengths to carry out the recommendation.

Evidence also exists of the use of strategies to gain commitment from clients, a variant of acceptability, for out-of-session actions. Mahrer, Gagnon, Fairweather, Boulet, and Herring (1994) analyzed 31 transcripts looking for therapist behaviors used to enlist client commitment to carry out postsession tasks. The most frequently used therapist behaviors were (a) therapist follow-up of a client-initiated idea; (b) highlighting the right, readiness, and willingness to carry out postsession tasks; (c) defining the behavior specifically and concretely; (d) using encouragement and pressure; (e) rehearsing and elaborating in-session; and (f) seeking a contractual agreement or commitment from the client. Mahrer et al. (1994) observed that therapists seemed to use methods repeatedly until commitment was achieved and that mutual cooperativeness between therapist and client facilitated the process. This investigation did not determine the most effective therapist behaviors, but only the most commonly used methods with the goal of gaining commitment from the client.
What Factors Affect Compliance?

Compliance, defined here as the extent to which clients implement the recommended homework, is viewed as an important indication of commitment, motivation, and involvement - client qualities essential to the change process. Compliance is clearly associated with positive outcomes. This section of our review is concerned solely with factors that contribute to compliance, including problem severity, client characteristics, therapist delivery methods, noncompliance, and assessment of compliance.

\section{Problem severity and homework compliance}

Results are mixed in detecting a relationship between problem severity and compliance with homework recommendations. Burns and Spangler (2000) explored the bidirectional causal relationship between compliance and depression without finding evidence for the influence of severity of depression on compliance. Similarly, Edelman and Chambless (1995) did not find a significant relationship between symptom severity and homework compliance with 52 clients in group therapy who were diagnosed with social phobia. However, clients judged more dependent tended to complete more homework. In contrast, Edelman and Chambless (1993) discovered a significant relationship between severity of symptoms and compliance with 56 clients who were diagnosed with agoraphobia. Perhaps symptom severity acts as a motivator to comply with whatever call to action is suggested by the therapist. The client may perceive the homework as a way to gain control of symptoms or to be actively engaged in symptom relief efforts. Conversely, severe disorders, problems, or complaints (e.g., major depression) may deprive the client of the energy and willingness to act on the therapist's recommendation. Both explanations seem plausible and may help explain the inconsistent findings.

\section{Client characteristics and homework compliance}

The idea that homework may be a better tactic with some types of clients presenting with specific characteristics has attracted almost no empirical attention, and very little may be concluded from the few investigations conducted thus far. Burns and Nolen-Hoeksema (1991) found that pretreatment expectations of 307 clients diagnosed with affective disorders were not related to homework compliance. 
Schmidt and Woolaway-Bickel (2000) found that the quality of the homework completed by 48 clients diagnosed with panic disorder is a better predictor of outcome than the amount of homework completed. They also found that older clients who were unemployed demonstrated higher quality homework. Leung and Heimberg (1996) discovered that clients diagnosed with social phobia $(n=104)$ who started treatment by completing homework recommendations tended to continue complying with later homework recommendations.

Finally, Addis and Jacobson (2000) provide evidence of the connection between common factors to therapy (i.e., client commitment) and homework compliance. They investigated the effects on outcome of homework compliance and of acceptance of a treatment rationale for CBT with 150 clients suffering from major depression, finding that both variables separately predicted outcome. Their correlation matrix revealed a significant relationship between homework compliance and acceptance of a treatment rationale $(r=.33, p<.01$, for early compliance; $r=.17, p<.05$, for midcompliance), suggesting that clients who "buy into" therapy are also motivated to complete homework.

Personality characteristics associated with homework compliance have not been investigated. Matching particular homework assignments to specific client personality characteristics (e.g., assigning journaling to an introspective client who likes to write) seems to be common practice, yet no supporting evidence has been published.

\section{Therapist delivery method and homework compliance}

Our review revealed the effectiveness of several therapist methods of delivering homework in gaining client compliance. Burns and Auerbach (1992) investigated the use of paradoxical inquiry on homework compliance with clients who were clinically depressed, finding the strategy of asking clients how they believed their lives could improve without changing the way they cope to be influential in gaining compliance. Cox, Tisdelle, and Culbert (1988) explored the difference between verbal and written behavioral recommendations with 30 outpatient clients, finding superior compliance with the written recommendations condition. Therapist reviews of previous homework and therapist competence both were related to homework compliance over 20 sessions in a study of 26 clinically depressed clients (Bryant et al., 1999). Less effective in gaining com- pliance were client collaboration, clarity of explanation, and the use of a rationale in a study with 25 clients diagnosed with depression over 235 sessions (Startup \& Edmonds, 1994). Finally, Worthington (1986) conducted a comprehensive study of homework compliance with 61 clients reporting career concerns to investigate whether client characteristics, therapist characteristics, or specific therapy variables were influential. Of the three, only the therapy variables of including homework early in therapy, a history of compliance, and whether the therapist first checked the client's attitude toward homework predicted compliance.

\section{Noncompliance with homework}

Only one study was found of therapist behaviors contributing to noncompliance, and this research was not specifically about homework and out-ofsession tasks. Patterson and Forgatch (1985) demonstrated that confronting and teaching behaviors (i.e., direct interventions) in session were significantly related to client noncompliance in session. Teaching and confrontation maximize the hierarchical nature of the therapist-client relationship. Recall that research on acceptability suggests that small changes that fit more with the client's perspective about his or her problem and what will lead to change may be a more effective tactic than teaching and confronting. However, this is only speculation, owing to the limited research on client noncompliance and therapist behaviors in recommending homework.

\section{Assessment of compliance}

A method for assessing whether clients did the out-of-session task as intended and the quality of what clients did is a challenge that remains to be addressed in research and practice. Only one study, by Schmidt and Woolaway-Bickel (2000), has attempted to assess the quality of completed homework. This was done using homework sheets that clients completed about the homework assignment and therapist ratings of the quality of what was done. Presently, therapists in practice seem to rely solely on the subjectivity of client self-reports. An example of a homework sheet appears in Figure 1. Similar sheets may be used to address the need for more accurate means of reporting what occurs between sessions. Note that clients are required to write something down, representing a kind of documentation, during the week between sessions about their homework efforts. This 


\section{Observing When Things are Better}

Observe the times when the thing(s) you are working on in counseling are not problems or when the problems are less. Describe the situation in the column below. Then in the next column, note the aspect of the situation that is different from the problem on which you are working in counseling. In the third column, note how the differences contribute to things being better. Finally, in the last column, rate from 0 to 100 how much you believe that the improved situation will last. $0=$ never happen again, $25=$ low probability, $50=$ moderately sure, $75=$ confident, $100=$ no doubt.

\begin{tabular}{cccc}
\hline $\begin{array}{c}\text { Situation (Exception } \\
\text { to the problem: } \\
\text { where? when? with } \\
\text { whom?) }\end{array}$ & $\begin{array}{c}\text { Difference from } \\
\text { problem situation }\end{array}$ & $\begin{array}{c}\text { How differences } \\
\text { make things better }\end{array}$ & Rating \\
\hline
\end{tabular}

Figure 1. Example of a sheet to document the client homework experience

may also facilitate a more specific discussion of homework experiences during the next session.

\section{Summary}

The practice of homework in psychotherapy is prevalent, consisting of many types of recommended out-of-session tasks. Homework is not confined to one theoretical orientation but is now being seen as a legitimate practice for psychotherapy in general. Research about homework compliance is in its infancy, and work remains to be done in the investigation of what types of homework work best for what types of clients under what kinds of conditions. Homework is theorized to serve multiple purposes in psychotherapy, but one of the most important may be as an indicator of client involvement and commitment to therapy as a method of change.

\section{Conceptual Model of the Homework Recommendation Process}

The process of recommending homework, as it exists currently in typical psychotherapy practice, should, we believe, be regarded as a set of actions. We propose a theoretically and empirically based, six-phase model of the homework recommendation process. It is based on social constructionism (e.g., Watzlawick, Weakland, \& Fisch, 1974; Gergen, 1985), strategic/systemic theories (Fisch, Weakland, \& Segal, 1986), and research findings of studies in our review. Research findings related to client acceptability and commitment are most pertinent. Figure 2 displays each of the six phases.
Homework tasks are formulated during Phase 1, in which client and therapist coconstruct actions to be performed in between sessions. The initial homework action may be formulated during Phase 1 by the therapist on the basis of the client's conceptualization of her or his situation. Proposing homework on the basis of the client's conceptualization helps ensure that the specific homework is a good fit for that particular client. During the Phase 1 formulation, the therapist is interested in understanding client attributions and the client's theory of change in regard to the presenting problem as well as the client's strengths. Client beliefs about the problem and strengths are assessed to provide information to aid in the formulation of a rationale for doing the homework. Homework formulations during Phase 1 are the outcomes of collaborative processes between clients and therapists. Phase 2 is the delivery phase. The therapist delivers the homework recommendation after a discussion of the upcoming task, which should include a rationale explaining its importance, as well as some preparation and planning to successfully carry out the task. In accordance with research findings about client acceptability of homework, the therapist designs a rationale and a homework task that fits with the client's strengths and belief system about the problem. The discussion and rationale promote understanding and help the client to view the task as realistic and not overly difficult to complete. Phase 3 is the receiving phase. During this phase, the client fits the homework task and accompanying rationale to existing schemata. This internal process results in the client's acceptance, rejection, or modification of the homework 


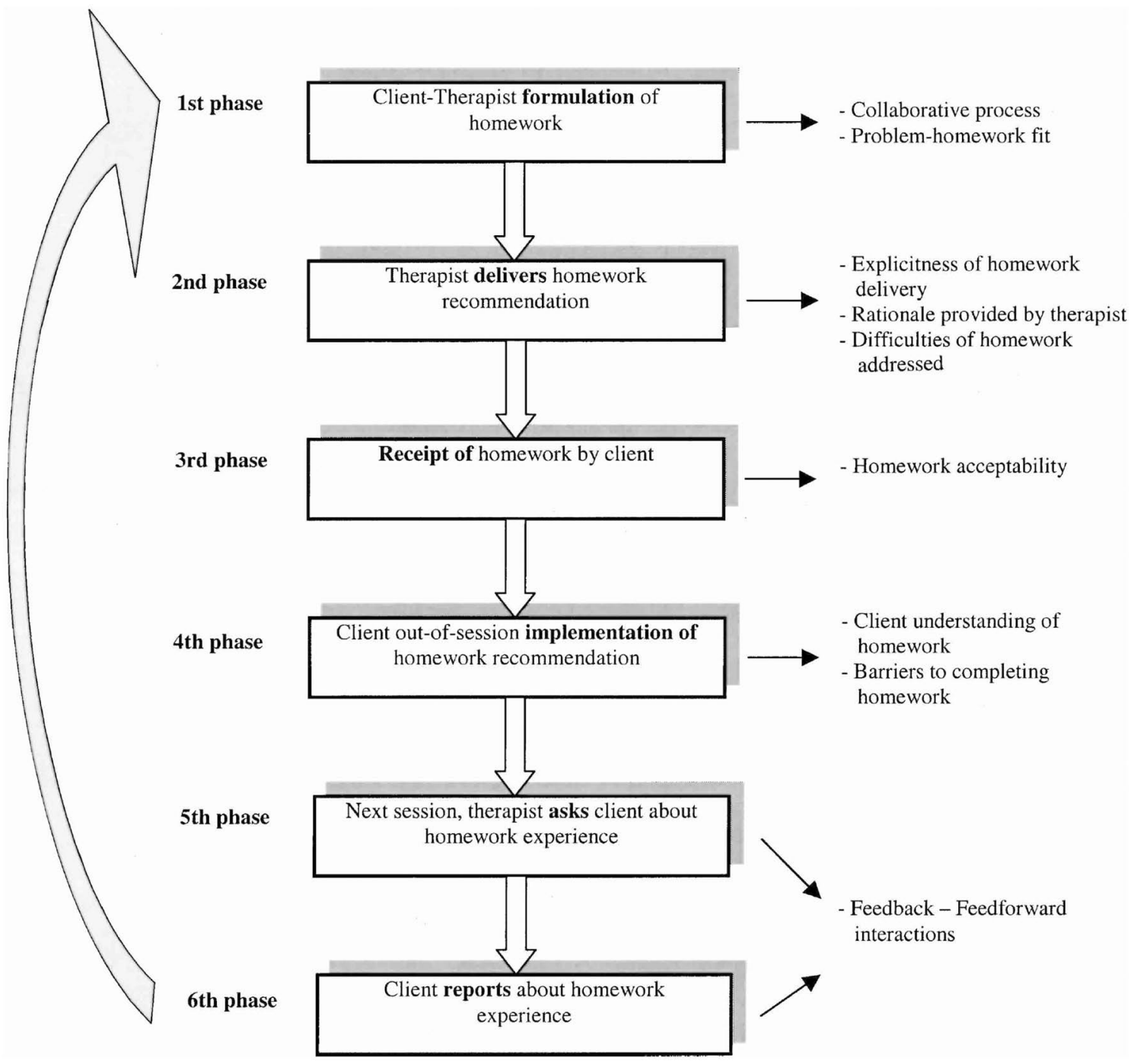

Figure 2. Six-phase model of the homework recommendation process

recommendation. Acceptance of the homework recommendation hinges on the level of match between the therapist's rationale for the assignment and the client's position concerning the problem (cf. Fisch et al., 1986, pp. 89-91). Matching rationales have been linked to higher levels of client acceptability (Scheel, Conoley, \& Ivey, 1998). Also influencing the client's acceptability are the strength of the therapeutic relationship, the perceived difficulty of the recommendation, and the degree of utilization of client strengths. Client deference to the therapist may determine whether the attitude toward the proposed homework is revealed.
The client leaves the therapy session and complies either completely, partially, or not at all with the homework recommendation, as represented by the degree of implementation of the constructed homework task (Phase 4). External forces that may serve to impinge or facilitate the client's efforts to complete the homework task influence Phase 4 activities. The client may, for example, have good intentions to follow through with the homework and then get sidetracked by such distractions as time, resources, unpredictable events, or other requirements such as job, family, or relationship responsibilities. The client's resolve to complete the homework in the midst 
of competing external forces acts as a mediating factor. Completion of the homework task is also contingent on the client's understanding of the homework task. The last component of the homework action is the next session, when client and therapist review the homework experience (Phases 5 and 6). Sometimes the therapist neglects to ask about the homework experience (Phase 5), and sometimes the client may hesitate to report about homework (Phase 6), perhaps because the client has not experienced success with the task. The process acts as a feedback-feed-forward interaction, because information gained from the last homework experience influences the next homework experience. This six-phase model, although based on findings from research about homework, needs empirical testing of the suppositions forwarded.

\section{Strategies for Recommending Homework in Psychotherapy}

Several strategies are recommended to gain client commitment to a proposed homework action and to maximize the likelihood of the client accurately understanding and implementing the homework task. In the following list, empirical support for each strategy is indicated in parentheses. An estimated skill level needed by the therapist is provided in brackets, along with the homework acceptability factors accounted for through the suggested strategy.

\section{Phase 1: Client-Therapist Formulation}

1. Collaborate with the client and give the client choices (Kazantzis \& Deane, 1999; Mahrer et al., 1994). "What are your ideas about something you could do during the week to work on this goal?" [High skill; acceptability factors: fit and influence]

\section{Phase 2: Therapist Delivery}

2. Indicate explicitly that the recommendation is a homework task (Mahrer et al., 1994). [Low skill; acceptability factor: difficulty]

3. Describe in detail the postsession behavior to be carried out (Mahrer et al., 1994). [Moderate skill; acceptability factor: difficulty]

4. Provide a rationale for how the homework activity will benefit the client that matches client's beliefs about his or her problem and how change may occur (Kazantzis \& Deane, 1999; Mahrer et al., 1994; Scheel, Conoley, \& Ivey, 1998). [High skill; acceptability factor: fit]

5. Match the client's level of ability with the recommended task (A. T. Beck et al., 1979; Glaser et al., 2000). [High skill; acceptability factors: fit, difficulty, and strengths]

6. Utilize client strengths through the tasks that are recommended (Conoley et al., 1994; Scheel, Conoley, \& Ivey, 1998). [High skill; acceptability factors: fit, difficulty, and strengths]

7. Provide a written description of the homework activity with a sheet on which clients will record their experiences during the next week (Cox et al., 1988; Schmidt \& Woolaway-Bickel, 2000; Levy \& Shelton, 1990). [Low skill; acceptability factors: difficulty]

\section{Phase 3: Client Receipt}

8. Consider strategies for overcoming potential difficulties (Kazantzis \& Deane, 1999). [High skill; acceptability factor: difficulty]

9. Ask the client how confident he or she is about completing the homework, and modify or renegotiate if the client is less confident (Kazantzis \& Deane, 1999). [High skill; acceptability factors: fit and strengths]

10. Write down the homework activity in case notes to keep an accurate record of what was recommended (Kazantzis \& Deane, 1999). [Low skill; acceptability factor: influence]

\section{Phase 4: Implementation}

11. Arrive at a contractual agreement (or at least a commitment) with the client that the postsession behavior will be carried out (Mahrer et al., 1994). "Is this something you will be able to do in the next week?" [Moderate skill; acceptability factor: fit, difficulty, and influence]

12. Try out the postsession behavior in session, perhaps through a role-play enactment (Mahrer et al., 1994). [High skill; acceptability factor: difficulty]

\section{Phase 5: Therapist Asks About Homework Experience}

13. Ask about the homework experience at the next session and review the completed homework 
sheet (Shelton \& Levy, 1981). [Moderate skill; acceptability factor: influence]

14. Provide praise for any homework carried out (Kazantzis \& Deane, 1999). [Moderate skill; acceptability factor: influence]

\section{Phase 6: Client Report of Homework Experience}

15. Assess and record the client's weekly performance with homework (Kazantzis \& Deane, 1999). [Low skill; acceptability factor: influence]

These strategies are not intended to be prescriptive but, instead, to be considered within a commonfactors framework. That is, the therapist's intent should be to gain client commitment and increase client involvement through adherence to the four acceptability components: matching client beliefs, utilizing client strengths, suggesting moderately difficult tasks, and employing social influence through the relationship.

\section{Implications for Future Research and Practice}

Certainly, both the proposed six-phase model and the strategies for recommending homework must be validated through empirical investigation. The suggested method of recommending homework is based on an acceptability model that was validated through research and demonstrated to be predictive of homework compliance. Strategies used by therapists in recommending homework that lead to noncompliance should be explored as well. Methods have been suggested that foster more intentional use of homework by practitioners. Attention to client understandings about homework after they leave the office is warranted. Clients' covert processes that are unknown to their therapists require much greater illumination if we are to know how homework and homework compliance relate to change processes. We encourage both researchers and practitioners to incorporate into treatment planning the actions of clients in between sessions. This has the potential to maximize the efficiency of psychotherapy in reaching positive outcomes by tapping into increased opportunities for change.

We encourage investigation of the link between the working alliance and homework compliance. Homework success may be tied to the strength of the therapeutic relationship. Research has demonstrated that clients are more prone to accept homework and cooperate when they view therapists as expert, interpersonally attractive, and trustworthy (Scheel, Hoggan, et al., 1998). When the therapeutic relationship is not solid, successful applications of homework may be less likely to occur.

We also encourage investigations that emphasize the common factors of therapy, pursuing questions such as "Are homework recommendations to clients associated with increased client involvement, more hopefulness, and greater client commitment to therapy?" and "Is homework compliance related positively to improvements in the working alliance?" We hypothesize that a homework recommendation would need to be carefully sculpted so that it fit well with the client's concerns and theory of change, was of no more than moderate difficulty, used client strengths, and was provided when the client judged the therapist as influential to realize increases in common change factors.

Cultural factors are essential to consider for an integrative perspective of homework intended for all clients within a common-factors framework. Fischer, Jome, and Atkinson (1998) offer what they term a reconceptualization of multicultural counseling and provide a place for homework through the ritual or intervention component of their model. Fischer et al. emphasize that the ritual or intervention must have cultural relevance for the client. They point to Jerome Frank's conceptualization of healing in therapy as "a ritual or procedure that requires the active participation of both the client and therapist that is believed by both to be the means of restoring the client's health" (Frank \& Frank, 1991, p. 43). Fischer et al. emphasize an approach in which rituals or interventions are relevant and effective when the therapeutic relationship, a shared worldview, and positive expectations are realized. A shared worldview is similar to the fit of the homework assignment with the client's view of the problem and how change occurs. The component, positive expectations for change, is in the same vein as the utilization of client strengths and the client's perception that the homework is not too difficult to implement. The therapeutic relationship would include trust and a view of the therapist as socially influential. We suggest research using the Fischer et al. multicultural perspective that pursues explanations of the cultural relevance of homework for clients.

More research and more attention in therapeutic practice seem important for the further devel- 
opment of homework recommendations as essential elements of therapy. The lack of attention to, and validation of, homework actions as an integral piece of therapeutic process may be attributed in part to the absence of homework in many accepted orientations to therapy. We acknowledge and offer the perspective that clients are continually engaged in therapeutic actions in between sessions, whether recommended by the therapist or not. Clients leave therapy sessions and, in various ways, always act on what occurred during therapy. Client out-of-session processes have not been emphasized enough in psychotherapy theory, research, and practice (cf. Hubble et al., 1999). Out-of-session client actions may consist only of thoughts about the in-session experience. Actions may also take a more tangible form of trying out something new in one's life, based on differences that were suggested and initiated in session.

The three stages of Hill and O'Brien's (1999) helping-skills model are (a) exploration, (b) insight, and (c) action. We suggest a nonlinear process involving these three components in which actions are occurring simultaneously with exploration and insight development. Homework actions may be a means of advancing exploration and developing insight. Therefore, according to the assumption that the outof-session action stage is occurring more-or-less constantly, psychotherapy, once initiated, has no boundaries as a change process. The process is initiated during the therapy session and continues out-of-session through actions of the client. The explicit recommendation of homework by the therapist provides a means to exert more structure on an already-occurring process. An action is recommended that may help break the problem pattern. Promoted here is a mindfulness about the homework recommendation process that promotes client acceptability and implementation, as well as client involvement and commitment to changing.

\section{References}

References marked with an asterisk indicate empirical, processrelated homework studies that were included in this review.

* Addis, M. E., \& Jacobson, N. S. (2000). A closer look at the treatment rationale and homework compliance in cognitive-behavioral therapy for depression. Cognitive Therapy and Research, 24, 313-326.
Beck, A. T., \& Haaga, D. A. F. (1992). The future of cognitive therapy. Psychotherapy, 29, 34-38.

Beck, A. T., Rush, A. J., Shaw, B. F., \& Emery, G. (1979). Cognitive therapy of depression. New York: Guilford Press.

Beck, A. T., \& Weishaar, M. E. (1995). Cognitive therapy. In R. J.Corsini \& D.Wedding (Eds.), Current psychotherapies (5th ed., (pp. 229-261). Itasca, IL: F. E. Peacock.

Beck, J. S. (1995). Cognitive therapy: Basics and beyond. New York: Guilford Press.

Boscolo, L., Cecchin, G., Hoffman, L., \& Penn, P. (1987). Milan systemic family therapy. New York: Basic Books.

Brown-Standridge, M. D. (1989). A paradigm for constructing of family therapy tasks. Family Process, 28, 471-489.

* Bryant, M. J., Simons, A. D., \& Thase, M. E. (1999). Therapist skills and patient variables in homework compliance: Controlling an uncontrolled variable in cognitive therapy outcome research. Cognitive Therapy and Research, 23, 381-399.

* Burns, D. D., \& Auerbach, A. H. (1992). Does homework compliance enhance recovery from depression? Psychiatric Annals, 22, 464-469.

Burns, D., \& Nolen-Hoeksema, S. (1991). Coping styles, homework compliance, and the effectiveness of cognitive-behavioral therapy. Journal of Consulting and Clinical Psychology, 59, 305-311.

* Burns, D. D., \& Spangler, D. L. (2000). Does psychotherapy homework lead to improvements in depression in cognitive-behavioral therapy or does improvement lead to increases in homework compliance?Journal of Consulting and Clinical Psychology, 68, 46-56.

Conoley, C. W., Conoley, J. C., Ivey, D. C., \& Scheel, M. J. (1991). Enhancing consultation by matching the consultee's perspectives. Journal of Counseling and Development, 69, 546-549.

* Conoley, C. W., Padula, M. A., Payton, D. S., \& Daniels, J. A. (1994). Predictors of client implementation of counselor recommendations: Match with problem, difficulty level, and building on client strengths. Journal of Counseling Psychology, 41, 3-7.

Corey, G. (2001). Theory and practice of counseling and psychotherapy (6th ed.). Belmont, CA: Brooks/Cole.

* Cox, D. J., Tisdelle, D. A., \& Culbert, J. P. (1988). Increasing adherence to behavioral homework assignments. Journal of Behavioral Medicine, 11, 519-522.

DeJong, P., \& Berg, I. K. (2002). Interviewing for solutions (2nd ed.). Pacific Grove, CA: Brooks/Cole.

De Shazer, S. (1988). Clues: Investigating solutions in brief therapy. New York: Norton. 
Detweiler, J. B., \& Whisman, M. A. (1999). The role of homework assignments in cognitive therapy for depression: Potential methods for enhancing adherence. Clinical Psychology: Science and Practice, 6, 267-282.

Edelman, R. E., \& Chambless, D. L. (1993). Compliance during sessions and homework in exposure-based treatment of agoraphobia. Behavioral Research and Therapy, 31, 767-773.

* Edelman, R. E., \& Chambless, D. L. (1995). Adherence during sessions and homework in cognitive-behavioral group treatment of social phobia. Behavioral Research and Therapy, 33, 573-577.

Fisch, R., Weakland, J. H., \& Segal, L. (1986). The tactics of change: Doing therapy briefly. San Francisco: Jossey-Bass.

Fischer, A. R., Jome, L. M., \& Atkinson, D. R. (1998). Reconceptualizing multicultural counseling: Universal healing conditions in a culturally specific context. Counseling Psychologist, 26, 525-588.

Frank, J. D., \& Frank, J. B. (1991). Persuasion and healing: A comparative study of psychotherapy (3rd ed.). Baltimore: Johns Hopkins University Press.

Gergen, K. J. (1985). The social constructionist movement in modern psychology. American Psychologist, 40, 266-275.

Glaser, N. M., Kazantzis, N., Deane, F. P., \& Oades, L. G. (2000). Critical issues in using homework assignments within cognitive-behavioral therapy for schizophrenia. Journal of Rational-Emotive and Cognitive-Behavioral Therapy, 18, 247-261.

Haley, J. (1991). Problem-solving therapy (2nd ed.). San Francisco: Jossey-Bass.

Hawes, E. C. (1993). Marriage counseling and enrichment. In O. C.Christensen (Ed.), Adlerian family counseling (pp. 125-163). Minneapolis, MN: Educational Media Corp.

Hay, C. E., \& Kinnier, R. T. (1998). Homework in counseling. Journal of Mental Health Counseling, 20, 122.

Hill, C. E., \& O'Brien, K. M. (1999). Helping skills: Facilitating exploration, insight, and action. Washington, DC: American Psychological Association.

Hill, C. E., Thompson, B. J., Cogar, M., \& Denman, D. W., III. (1993). Beneath the surface of long-term therapy: Therapist and client report of their own and each other's covert processes. Journal of Counseling Psychology, 40, 278-287.

Hubble, M. A., Duncan, B. L., \& Miller, S. D. (Eds.). (1999). The heart and soul of change: What works in therapy. Washington, DC: American Psychological Association.
Kazantzis, N. (2000). Power to detect homework effects in psychotherapy outcome research. Journal of Consulting and Clinical Psychology, 68, 166-170.

* Kazantzis, N., \& Deane, F. (1999). Psychologists' use of homework assignments in clinical practice. Professional Psychology: Research and Practice, 20, 581-585.

* Kazantzis, N., Deane, F. P., \& Ronan, K. R. (2000). Homework assignments in cognitive and behavioral therapy: A meta-analysis. Clinical Psychology: Science and Practice, 7, 189-202.

Kazantzis, N., \& Lampropoulos, G. K. (2002a). Reflecting on homework in psychotherapy: What can we conclude from research and experience?Journal of Clinical Psychology, 58, 577-585.

Kazantzis, N., \& Lampropoulos, G. K. (2002b). The use of homework in psychotherapy: An introduction. Journal of Clinical Psychology, 58, 487-488.

Kazdin, A. E. (1980). Acceptability of alternative treatments for deviant children. Journal of Applied Behavior Analysis, 13, 259-273.

* Leung, A. W., \& Heimberg, R. G. (1996). Homework compliance, perceptions of control, and outcome of cognitive-behavioral treatment of social phobia. Behavior Research and Therapy, 34, 423-432.

Levy, R. L., \& Shelton, J. L. (1990). Tasks in brief therapy. In R. A.Wells \& V.Giannetti (Eds.), Handbook of brief therapies (pp. 145-163). Plenum Press.

* Mahrer, A. R., Gagnon, R., Fairweather, D. R., Boulet, D. B., \& Herring, C. B. (1994). Client commitment and resolve to carry out postsession behaviors. Journal of Counseling Psychology, 41, 407-414.

* Mahrer, A. R., Nordin, S., \& Miller, L. S. (1995). If the client has this kind of problem, prescribe that kind of post-session behavior. Psychotherapy: Theory, Research, Practice, Training, 32, 194-203.

Morgan, B., \& MacMillan, P. (1999). Helping clients move toward constructive change: A three-phase integrative counseling model. Journal of Counseling and Development, 77, 153-159.

Neimeyer, R. A., \& Feixas, G. (1990). The role of homework and skill acquisition in the outcome of group cognitive therapy for depression. Behavior Therapy, 21, 281-292.

Patterson, G. R., \& Forgatch, M. S. (1985). Therapist behavior as a determinant for client noncompliance: A paradox for the behavior modifier. Journal of Consulting and Clinical Psychology, 53, 846-851.

Persons, J. B., Burns, D. D., \& Perloff, J. M. (1988). Predictors of dropout and outcome in cognitive therapy for depression in a private practice setting. Cognitive Therapy and Research, 12, 557-575. 
Reimers, T. M., Wacker, D. P., \& Koeppl, G. (1987). Acceptability of behavioral interventions: A review of the literature. School Psychology Review, 16, 212-227.

Rennie, D. L. (1992). Qualitative analysis of the client's experience of psychotherapy: The unfolding of reflexivity. In S. G.Toukmanian \& D. L.Rennie (Eds.), Psychotherapy process research: Paradigmatic and narrative approaches (pp. 211-233). Newbury Park, CA: Sage.

Scheel, M. J., Conoley, C. W., \& Ivey, D. C. (1998). Using client positions as a technique for increasing the acceptability of marriage therapy interventions. American Journal of Family Therapy, 26, 203-214.

Scheel, M. J., Hoggan, K., Willie, D., McDonald, K., \& Tonin, S. (1998). Client understanding of homework determined through therapist delivery.Poster presented at the 106th Annual Convention of the American Psychological Association, San Francisco.

* Scheel, M. J., Seaman, S., Roach, K., Mullin, T., \& Blackwell Mahoney, K. (1999). Client implementation of therapist recommendations predicted by client perception of fit, difficulty of implementation, and therapist influence. Journal of Counseling Psychology, 46, $1-9$.

* Schmidt, N. B., \& Woolaway-Bickel, K. (2000). The effects of treatment compliance on outcome in cognitive-behavioral therapy for panic disorder: Quality versus quantity. Journal of Consulting and Clinical Psychology, 68, 13-18.
Shelton, J. L., \& Levy, R. L. (1981). Behavioral assignments and treatment compliance: A handbook of clinical strategies. Champaign, IL: Research Press.

Spiegler, M. D., \& Guevremont, D. C. (1998). Contemporary behavior therapy (3rd ed.). Pacific Grove, CA: Brooks/Cole.

* Startup, M., \& Edmonds, J. (1994). Compliance with homework assignments in cognitive-behavioral psychotherapy for depression: Relation to outcome and methods of enhancement. Cognitive Therapy and Research, 18, 567-579.

Wampold, B. E. (2001). The great psychotherapy debate: Models, methods, and findings. Mahwah, NJ: Erlbaum.

Watzlawick, P., Weakland, J. H., \& Fisch, R. (1974). Change: Principles of problem formulation and problem resolution. New York: Norton.

Wells, R. A. (1994). Planned short-term treatment (2nd ed.). New York: Free Press.

* Worthington, E. L. (1986). Client compliance with homework directives during counseling. Journal of Counseling Psychology, 33, 124-130.

Zettle, R. D., \& Hayes, S. C. (1987). Component and process analysis of cognitive therapy. Psychological Reports, 61, 939-953. 